\title{
ANALISIS INDEKS KEPUASAN MASYARAKAT DARI PELAYANAN PUSKESMAS LUBUK LANDAI KABUPATEN BUNGO
}

\author{
Darham, Dian Romadani \\ Program Studi Manajemen Fakultas Ekonomi \\ Universitas Muara Bungo
}

\begin{abstract}
ABSTRAK
Tujuan dilakukan penelitian ini adalah Untuk mengetahui indeks kepuasan masyarakat dari pelayanan Puskesmas Tanah Sepenggal Kabupaten Bungo dan Untuk mengetahui Faktor-faktor yang paling dominan mempengaruhi Indeks Kepuasan Masyarakat dari pelayanan Puskesmas Tanah Sepenggal Kabupaten Bungo.

Metode penelitian ini bersifat Deskriptif Kuantitatif dan menggunakan analisa kualitatif untuk mendiskripsikan data-data. Populasi adalah masyarakat tahun 2018 sebanyak 280 orang, denganinsidental sampling sampel sebanyak 162 orang.

Hasil penelitian ini, Indeks Kepuasan Masyarakat terhadap pelayanan publik di Puskesmas Lubuk Landai Kecamatan Tanah Sepenggal Kabupaten Bungo dengan menggunakan 9 indikator sesuai dengan PermenPAN-RB Nomor 14 Tahun 2017 diperoleh Nilai Komulatif Indeks Kepuasan masyarakat sebesar 74 atau dapat dikatakan kurang baik dengan Mutu Pelayanan $\mathrm{C}$, dengan faktor dominan adalah indikator sarana dan prasarana agar lebih ditingkatkan.
\end{abstract}

Kata Kunci : Indeks Kepuasan, Pelayanan

\section{Pendahuluan}

Puskesmas Tanah Sepenggal merupakan salah satu Puskesmas yang terdapat di Kabupaten Bungo yang diberikan kewenangan yang sama untuk melayani masyarakat dengan wilayah kerja 10 dusun.Rendahnya kinerja pelayanan akan membangun citra buruk pada Puskesmas, dimana pasien yang merasa tidak puas akan menceritakan kepada rekan-rekannya. Begitu juga sebaliknya, semakin tinggi kinerja pelayanan yang diberikan akan menjadi nilai plus bagi Puskesmas, dalam hal ini pasien akan merasa puas terhadap pelayanan yang diberikan oleh Puskesmas. Seperti pada tabel dibawah ini memperlihatkan jumlah kunjungan masyarakat selama tahun 2018 .

Tabel 1.3 Jumlah Kunjungan Puskesmas Tanah Sepenggal Tahun 2018

\begin{tabular}{|r|l|r|r|r|r|}
\hline \multicolumn{1}{|c|}{ No } & \multicolumn{1}{|c|}{ Bulan } & \multicolumn{1}{c|}{ Umum } & \multicolumn{1}{c|}{ BPJS } & \multicolumn{1}{c|}{ SKTM } & \multicolumn{1}{c|}{ Jumlah } \\
\hline 1 & Januari & 427 & 254 & 35 & 716 \\
\hline 2 & Februari & 455 & 216 & 30 & 701 \\
\hline 3 & Maret & 487 & 218 & 18 & 723 \\
\hline 4 & April & 490 & 201 & 29 & 720 \\
\hline 5 & Mei & 398 & 182 & 19 & 599 \\
\hline 6 & Juni & 328 & 159 & 13 & 500 \\
\hline 7 & Juli & 482 & 218 & 27 & 727 \\
\hline 8 & Agustus & 444 & 222 & 20 & 686 \\
\hline 9 & September & 445 & 285 & 22 & 752 \\
\hline
\end{tabular}




\begin{tabular}{|r|l|r|r|r|r|}
\hline 10 & Oktober & 536 & 261 & 23 & 820 \\
\hline 11 & Nopember & 356 & 230 & 24 & 610 \\
\hline 12 & Desember & 362 & 284 & 20 & 667 \\
\hline \multicolumn{2}{c}{ total } & 5210 & 2730 & 280 & $\mathbf{8 2 2 1}$ \\
\hline
\end{tabular}

Sumber : Puskesmas Tanah Sepenggal, 2018

Berdasarkan observasi awal peneliti pada Puskesmas, peneliti tertarik untuk melakukan penelitian mengenai pelayanan yang diterima pasien yang menggunakan SKTM, hal ini dikarenakan adanya keluhan yang disampaikan masyarakat berkenaan dengan pelayanan yang diberikan puskesmas, di antaranya adalah perbedaan pelayanan antara SKTM dengan pasien lainnya, baik dari sisi waktu pelayanan maupun jenis obat yang diberikan, padahal jika merujuk data di atas maka jumlah pasien yang menggunakan SKTM sangat sedikit jika dibandingkan pasien lainnya. Selain itu keterlambatan petugas juga dikeluhkan oleh pasien SKTM, kondisi ini membuat mereka jadi menunggu terlalu lama.

Berdasarkan paparan tersebut di atas, maka penulis tertarik untuk melakukan penelitian dengan judul "Analisis Indeks Kepuasan Masyarakat dari Pelayanan Puskesmas Tanah Sepenggal Kabupaten Bungo". Berdasarkan uraian yang telah dikemukakan di atas maka yang menjadi rumusan masalah dalam penelitian ini adalah:

1. Bagaimana indeks kepuasan masyarakat dari pelayanan Puskesmas Tanah Sepenggal Kabupaten Bungo?

2. Faktor-faktor apa yang paling dominan mempengaruhi Indeks Kepuasan Masyarakat dari Pelayanan Puskesmas Tanah Sepenggal Kabupaten Bungo? yaitu:

tujuan penelitian yang ingin dicapai

1. Untukmengetahui indeks kepuasan masyarakat dari pelayanan Puskesmas Tanah Sepenggal Kabupaten Bungo.

2. Untukmengetahui Faktor-faktor yangpaling dominan mempengaruhi Indeks Kepuasan Masyarakat dari pelayanan Puskesmas Tanah Sepenggal Kabupaten Bungo.
IKM (Indeks Kepuasan Masyarakat)

Pengertian IKM (Indeks Kepuasan Masyarakat)

Peraturan Menteri Pendayagunaan Aparatur Negara Dan Reformasi Birokrasi Republik Indonesia Nomor 14 Tahun 2017 Tentang Pedoman Penyusunan Survei Kepuasan Masyarakat Unit Penyelenggara Pelayanan Publik dinyatakan bahwa Indeks Kepuasan Masyarakat adalah hasil pengukuran dari kegiatan Survei Kepuasan Masyarakat berupa angka. Angka ditetapkan dengan skala 1 (satu) sampai dengan 4 (empat). Sedangkan Kepuasan masyarakat adalah hasil pendapat dan penilaian masyarakat terhadap kinerja pelayanan yang diberikan kepada aparatur penyelenggara pelayanan publik.

Salah satu upaya untuk meningkatkan kualitas pelayanan publik, sebagaimana diamanatkan dalam Undang-undang Republik Indonesia Nomor Tahun 2000 tentang Program Pembangunan Nasional (PROPENAS), perlu disusun indeks kepuasan masyarakat sebagai tolok ukur untuk menilai tingkat kualitas pelayanan.

\section{Indikator IKM (Indeks Kepuasan Masyarakat) \\ Berdasarkan Peraturan Menteri}

Pendayagunaan Aparatur Negara Dan Reformasi Birokrasi Republik Indonesia Nomor 14 Tahun 2017 Tentang Pedoman Penyusunan Survei Kepuasan Masyarakat Unit Penyelenggara Pelayanan Publik maka pengukuran indeks kepuasan masyarakat adalah sebagai berikut:

1. Persyaratan

Persyaratan adalah syarat yang harus dipenuhi dalam pengurusan suatu jenis pelayanan, baik persyaratan teknis maupun administratif.

2. Sistem, Mekanisme, dan Prosedur 
Prosedur adalah tata cara pelayanan yang dibakukan bagi pemberi dan penerima pelayanan, termasuk pengaduan.

3. Waktu Penyelesaian

Waktu Penyelesaian adalah jangka waktu yang diperlukan untuk menyelesaikan seluruh proses pelayanan dari setiap jenis pelayanan.

4. Biaya/Tarif

Biaya/Tarif adalah ongkos yang dikenakan kepada penerima layanan dalam mengurus dan/atau memperoleh pelayanan dari penyelenggara yang besarnya ditetapkan berdasarkan kesepakatan antara penyelenggara dan masyarakat.

5. Produk Spesifikasi Jenis Pelayanan Produk spesifikasi jenis pelayanan adalah hasil pelayanan yang diberikan dan diterima sesuai dengan ketentuan yang telah ditetapkan Produk pelayanan ini merupakan hasil dari setiap spesifikasi jenis pelayanan.

6. Kompetensi Pelaksana
Kompetensi Pelaksana adalah kemampuan yang harus dimiliki oleh pelaksana meliputi pengetahuan, keahlian, keterampilan, dan pengalaman.

7. Perilaku Pelaksana

Perilaku Pelaksana adalah sikap petugas dalam memberikan pelayanan.

8. Penanganan Pengaduan, Saran dan Masukan

Penanganan pengaduan, saran dan masukan, adalah tata cara pelaksanaan penanganan pengaduan dan tindak lanjut.

9. Sarana dan prasarana

Sarana adalah segala sesuatu yang dapat dipakai sebagai alat dalam mencapai maksud dan tujuan. Prasarana adalah segala sesuatu yang merupakan penunjang utama terselenggaranya suatu proses (usaha, pembangunan, proyek). Sarana digunakan untuk benda yang bergerak (komputer, mesin) dan prasarana untuk benda yang tidak bergerak

(gedung).

\section{Kerangka Konseptual}

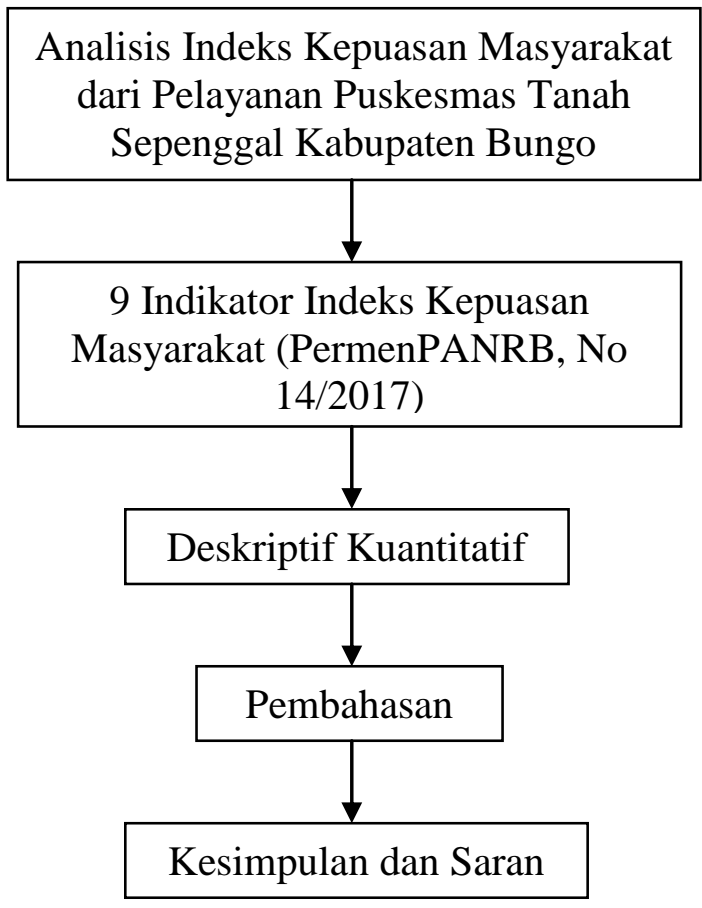




\section{METODOLOGI PENELITIAN}

Objek Penelitian

Objek penelitian adalah pelayanan di Puskesmas Lubuk Landai Kecamatan Tanah Sepenggal Kabupaten Bungo.Jenis penelitian ini adalah penelitian deskriptif kuantitatif dengan sumber data yang digunakan dalam penelitian ini dapat dikelompokkan menjadi dua yaitu :Data Primer dan Data Sekunder. Data primer yang digunakan dalam penelitian ini berupa kuesioner

\section{Populasi dan Sampel}

Dalam penelitian ini yang menjadi populasi adalah masyarakat yang mendapatkan pelayanan yang diberikan oleh Puskesmas Tanah Sepenggal Kabupaten Bungo dengan menggunakan SKTM (Surat Keterangan Tidak Mampu) tahun 2018 sebanyak 280 orang,pengambilan sampel menggunakan Krejcie and Morgan. maka jumlah sampel dalam penelitian ini 162 orang.

\section{Definisi Operasional Variabel}

\begin{tabular}{|c|c|c|c|}
\hline Variabel & Definisi Operasional & Indikator & $\begin{array}{c}\text { Skala } \\
\text { Pengukuran }\end{array}$ \\
\hline $\begin{array}{c}\text { Indeks } \\
\text { Kepuasan } \\
\text { Masyarakat } \\
\text { (IKM) } \\
\text { PermenPAN- } \\
\text { RB } \\
\text { No. } 14 / 2017\end{array}$ & $\begin{array}{l}\text { data dan informasi } \\
\text { tentang tingkat } \\
\text { kepuasan masyarakat } \\
\text { yang diperoleh dari } \\
\text { hasil pengukuran } \\
\text { secara kuantitatif dan } \\
\text { kualitatif atas } \\
\text { pendapat masyarakat } \\
\text { dalam memperoleh } \\
\text { pelayanan dari } \\
\text { aparatur } \\
\text { penyelenggara } \\
\text { pelayanan publik } \\
\text { dengan } \\
\text { membandingkan } \\
\text { antara harapan dan } \\
\text { kebutuhannya. }\end{array}$ & $\begin{array}{l}\text { 1. Persyaratan } \\
\text { 2. Sistem, Mekanisme, } \\
\text { dan Prosedur } \\
\text { 3. Waktu Penyelesaian } \\
\text { 4. Biaya/Tarif } \\
\text { 5. Produk Spesifikasi } \\
\text { Jenis Pelayanan } \\
\text { 6. Kompetensi Pelaksana } \\
\text { 7. Perilaku Pelaksana } \\
\text { 8. Penanganan } \\
\text { Pengaduan, Saran dan } \\
\text { Masukan } \\
\text { 9. Sarana dan prasarana }\end{array}$ & Likert \\
\hline
\end{tabular}

Sumber: PermenPAN-RB Nomor 14 Tahun 2017

\section{Pengambilan Kesimpulan}

Berdasarkan Peraturan Menteri

Pendayagunaan Aparatur Negara Dan

Reformasi Birokrasi Republik Indonesia Nomor 14 Tahun 2017 Tentang Pedoman Penyusunan Survei Kepuasan Masyarakat Unit Penyelenggara Pelayanan Publik maka nilai dihitung dengan menggunakan "nilai rata-rata tertimbang" masing-masing unsur pelayanan. Dalam penghitungan survei kepuasan masyarakat terhadap unsur-unsur pelayanan yang dikaji, setiap unsur pelayanan memiliki penimbang yang sama. Nilai penimbang ditetapkan dengan rumus, sebagai berikut:

$$
\text { Bobot nilai rata }- \text { rata tertimbang }=\frac{\text { jumlah bobot }}{\text { Jumlah unsur }}=\frac{1}{9}+0,11
$$

Untuk memperoleh nilai IKM unit pelayanan digunakan pendekatan nilai ratarata tertimbang dengan rumus sebagai berikut: 


$$
I K M=\frac{\text { Total dari Nilai Persepsi Per Unsur }}{\text { Total unsur yang terisi }} \times \text { Nilai Penimbang }
$$

Untuk memudahkan interpretasi terhadap penilaian IKM yaitu antara 25 - 100 maka hasil penilaian tersebut diatas dikonversikan dengan nilai dasar 25, dengan rumus:

IKM Unit Pelayanan x 25

Nilai Persepsi, Interval IKM, Interval Konversi IKM, Mutu Pelayanan dan Kinerja Unit Pelayanan

\begin{tabular}{|c|c|c|c|l|}
\hline $\begin{array}{c}\text { Nilai } \\
\text { Persepsi }\end{array}$ & $\begin{array}{c}\text { Nilai } \\
\text { Interval } \\
\text { IKM }\end{array}$ & $\begin{array}{c}\text { Nilai } \\
\text { Interval } \\
\text { Konversi } \\
\text { IKM }\end{array}$ & $\begin{array}{c}\text { Mutu } \\
\text { Pelayanan }\end{array}$ & $\begin{array}{c}\text { Kinerja } \\
\text { Unit } \\
\text { Pelayanan }\end{array}$ \\
\hline 1 & $1,00-2,5996$ & $25,00-64,99$ & $\mathrm{D}$ & Tidak baik \\
\hline 2 & $2,60-3,064$ & $65,00-76,60$ & $\mathrm{C}$ & Kurang baik \\
\hline 3 & $3,0644-3,532$ & $76,61-88,30$ & $\mathrm{~B}$ & Baik \\
\hline 4 & $3,5324-4,00$ & $88,31-100,00$ & $\mathrm{~A}$ & Sangat baik \\
\hline
\end{tabular}

Sumber : PermenPAN-RB Nomor 14 Tahun 2017

Menghitung Nilai Rata-Rata Masing-Masing Unsur Pelayanan dengan rumus sebagai berikut:

Nilai Rata-Rata Per Unsur = Jumlah nilai per unsur : jumlah responden

Hasil dari perhitungan tersebut diperoleh nilai rata-rata sebagai berikut:

Tabel 4.15 Rekapitulasi Rata-rata Tanggapan Responden

\begin{tabular}{|c|l|c|c|}
\hline No & \multicolumn{1}{|c|}{ Indikator } & $\begin{array}{c}\text { Jumlah } \\
\text { nilai }\end{array}$ & Rata \\
\hline 1 & Persyaratan & 522 & 3,22 \\
\hline 2 & Sistem, Mekanisme, dan Prosedur & 543 & 3,35 \\
\hline 3 & Waktu Penyelesaian & 465 & 2,87 \\
\hline 4 & Biaya/Tarif & 495 & 3,06 \\
\hline 5 & Produk Spesifikasi Jenis Pelayanan & 523 & 3,23 \\
\hline 6 & Kompetensi Pelaksana & 555 & 3,43 \\
\hline 7 & Perilaku Pelaksana & 452 & 2,79 \\
\hline 8 & Penanganan Pengaduan, Saran dan Masukan & 420 & 2,59 \\
\hline 9 & Sarana dan prasarana & 369 & 2,28 \\
\hline
\end{tabular}

Menghitung Nilai Rata-Rata tertimbang masing-masing unsur pelayanan dengan rumus sebagai berikut: 
Bobot nilai rata - rata tertimbang $=\frac{\text { jumlah bobot }}{\text { Jumlah } u n s u r}=\frac{1}{9}+0,11$

NRR tertimbang per unsur $=$ NRR per unsur $\mathrm{x} 0,011$

Hasil penghitungan tersebut diperoleh nilai sebagai berikut:

Nilai tertimbang

\begin{tabular}{|c|l|c|c|}
\hline No & \multicolumn{1}{|c|}{ Indikator } & Rata & $\begin{array}{c}\text { NRR } \\
\text { Tertimbang }\end{array}$ \\
\hline 1 & Persyaratan & 3,22 & 0,35 \\
\hline 2 & Sistem, Mekanisme, dan Prosedur & 3,35 & 0,37 \\
\hline 3 & Waktu Penyelesaian & 2,87 & 0,32 \\
\hline 4 & Biaya/Tarif & 3,06 & 0,34 \\
\hline 5 & Produk Spesifikasi Jenis Pelayanan & 3,23 & 0,36 \\
\hline 6 & Kompetensi Pelaksana & 3,43 & 0,38 \\
\hline 7 & Perilaku Pelaksana & 2,79 & 0,31 \\
\hline 8 & Penanganan Pengaduan, Saran dan Masukan & 2,59 & 0,28 \\
\hline 9 & Sarana dan prasarana & 2,28 & 0,25 \\
\hline
\end{tabular}

Menghitung Nilai Indeks penilaian tersebut diatas dikonversikan Kepuasan Masyarakat secara dengan nilai dasar 25, dengan rumus keseluruhan . Untuk memudahkan Indeks Kepuasan Masyarakat (IKM) interpretasi terhadap penilaian IKM PermenPAN-RB No.14/2017 sebagai yaitu antara 25 - 100 maka hasil berikut:

IKM Unit Pelayanan x 25

Diperoleh hasil sebagai berikut:

$\mathrm{IKM}=\mathbf{2 , 9 6} \times 25=74$

Jadi hasil yang didapatkan secara menyeluruh untuk indeks kepuasan masyarakat pada pelayanan publik di
Puskesmas Tanah Sepenggal Kabupaten Bungo yaitu: Mutu Pelayanan C serta Kinerja Unit Pelayanan Kurang Baik dan Nilai IKM setelah dikonversi adalah 74. Sebagaimana rumus PermenPANRB Nomor 14 Tahun 2017 sebagai berikut: 


\section{Nilai Persepsi, Interval IKM, Interval Konversi IKM, Mutu Pelayanan dan Kinerja Unit Pelayanan}

\begin{tabular}{|c|c|c|c|l|}
\hline $\begin{array}{c}\text { Nilai } \\
\text { Persepsi }\end{array}$ & $\begin{array}{c}\text { Nilai } \\
\text { Interval } \\
\text { IKM }\end{array}$ & $\begin{array}{c}\text { Nilai } \\
\text { Interval } \\
\text { Konversi } \\
\text { IKM }\end{array}$ & $\begin{array}{c}\text { Mutu } \\
\text { Pelayanan }\end{array}$ & $\begin{array}{c}\text { Kinerja } \\
\text { Unit } \\
\text { Pelayanan }\end{array}$ \\
\hline 1 & $1,00-2,5996$ & $25,00-64,99$ & D & Tidak baik \\
\hline 2 & $2,60-3,064$ & $65,00-76,60$ & C & Kurang baik \\
\hline 3 & $3,0644-3,532$ & $76,61-88,30$ & B & Baik \\
\hline 4 & $3,5324-4,00$ & $88,31-100,00$ & A & Sangat baik \\
\hline
\end{tabular}

Sumber : PermenPAN-RB Nomor 14 Tahun 2017

Berdasarkan tabel di atas diketahui bahwa indeks kepuasan masyarakat pada pelayanan publik di Puskesmas Tanah Sepenggal Kabupaten Bungo yaitu $\mathrm{C}$ dengan kategori kurang baik, hal ini tidak terlepas dari beberapa penilaian buruk yang diberikan masyarakat akibat dari ketidakpuasan mereka terhadap pelayanan yang diberikan Puskesmas Tanah Sepenggal Kabupaten Bungo.

Faktor-faktor yang paling dominan mempengaruhi Indeks Kepuasan Masyarakat dari pelayanan Puskesmas Tanah Sepenggal Kabupaten Bungo Rekapitulasi Ratarata Tanggapan Responden

\begin{tabular}{|c|l|c|c|c|}
\hline No & \multicolumn{1}{|c|}{ Indikator } & $\begin{array}{c}\text { Jumlah } \\
\text { nilai }\end{array}$ & Rata & Kategori \\
\hline 1 & Persyaratan & 522 & 3,22 & Baik \\
\hline 2 & Sistem, Mekanisme, dan Prosedur & 543 & 3,35 & Baik \\
\hline 3 & Waktu Penyelesaian & 465 & 2,87 & Kurang baik \\
\hline 4 & Biaya/Tarif & 495 & 3,06 & Kurang baik \\
\hline 5 & Produk Spesifikasi Jenis Pelayanan & 523 & 3,23 & Baik \\
\hline 6 & Kompetensi Pelaksana & 555 & 3,43 & Baik \\
\hline 7 & Perilaku Pelaksana & 452 & 2,79 & Kurang baik \\
\hline 8 & Penanganan Pengaduan, Saran dan & 420 & 2,59 & Kurang baik \\
& Masukan & & & \\
\hline 9 & Sarana dan prasarana & 369 & 2,28 & Kurang baik \\
\hline
\end{tabular}

Tabel di atas menunjukan bahwa faktor yang mempengaruhi indek kepuasan masy

arakat terhadap pelayanan yang diberikan Puskesmas yaitu Kompetensi Pelaksana,Pelaksana yaitu berupa kemampuan yang harus dimiliki oleh pelaksana meliputi pengetahuan, keahlian, keterampilan, dan pengalaman dengan nilai rata-rata 3,43 sedangkan penilaian rendah pada faktor-faktor Sarana dan prasaranasebesar 2,28 yang mempengaruhi kepuasan dan kenyamanan masyarakat seperti ruang tunggu yang tidak representative dan fasilitas air bersih untuk fasilitas kebersihan.

\section{Pembahasan}

Berdasarkan hasil pengukuran terhadap indeks kepuasan masyarakat pada pelayanan publik di Puskesmas 
Tanah Sepenggal Kabupaten Bungo yaitu: Mutu Pelayanan C serta Kinerja Unit Pelayanan Kurang Baik dan Nilai IKM setelah dikonversi adalah 74 . Kondisi ini menggambarkan bahwa masyarakat yang mendapatkan pelayanan di Puskesmas Tanah Sepenggal Kabupaten Bungo merasa kurang puas dengan pelayan yang diberikan.

Ketidakpuasan masyarakat yang mendapatkan pelayanan di Puskesmas Tanah Sepenggal Kabupaten Bungo ditunjukan dengan beberapa indikator,nilai terendah pada indikator Sarana dan prasarana yakni sebesar 2,28, hal ini dikarenakan banyaknya keluhan dari responden berkenaan dengan sarana yang terdapat di Puskesmas Tanah Sepenggal Kabupaten Bungo. Salah satu responden mengatakan bahwa masih terdapat kekurangan dalam sarana yang terdapat di Puskesmas seperti ketersediaan air dan WC umum untuk keluarga pasien yang tidak memadai. Di samping itu fasilitas yang tersedia seperti ruang tunggu yang kurang nyaman dan menyebabkan pasien merasa ditelantarkan.

Nilai rata-rata yang diperoleh Dimana yang tertinggi pada indikator Sistem, Mekanisme, dan Prosedur yakni sebesar 3,35, hal ini dapat dipahami karena Puskesmas Tanah Sepenggal Kabupaten Bungo telah menjalani prosedur yang ditetapkan. Serta pada indikator Kompetensi Pelaksana memperoleh nilai sebesar 3,43 hal ini tidak terlepas dari tenaga kesehatan yang telah memiliki kompetensi dibidangnya sesuai dengan latar belakang pendidikan mereka,

\section{Kesimpulan}

1. Dari 9 indikator sesuai dengan PermenPAN-RB Nomor 14 Tahun 2017 diperoleh Nilai Komulatif Indeks Kepuasan masyarakat sebesar 74 atau dapat dikatakan kurang baik dengan Mutu Pelayanan C serta Kinerja Unit Pelayanan Baik berdasarkan kategori penialain yang telah disesuaikan dariPermenPAN-RB Nomor 14 Tahun 2017.

2. Faktor-faktor yang paling dominan mempengaruhi Indeks Kepuasan Masyarakat dari pelayanan Puskesmas diantaranya adalah Kompetensi Pelaksana yaitu berupa kemampuan yang harus dimiliki oleh pelaksana meliputi pengetahuan, keahlian, keterampilan, dan pengalaman.

Saran

Diperlukan dukungan dari Pemerintah Daerah untuk meningkatkan sarana dan prasarana yang terdapat di Puskesmasagar meningkatkan pelayanan dan mempercepat proses pelayanan dan perilaku pegawai menjadi lebih baik di Lubuk Landai Kecamatan Tanah Sepenggal Kabupaten Bungo, agar kepuasan masyarakat menjadi lebih baik.

\section{DAFTAR PUSTAKA}

Anwar Prabu Mangkunegara. 2007. Manajemen Sumber Daya Manusia Perusahaan. Bandung: PT. Remaja Rosdakarya

Bragan. 1992. Kinerja Blınıus Pelayanan Publik. University Press, Yogyakarta.

Effendy, Onong Uhcjana. 2002. Ilmu Komunikasi Teori dan Praktek. Bandung: PT. Remaja Rosdakarya.

Fandy Tjiptono, 1997, Strategi Pemasaran, Edisi 1, Penerbit Andi, Yogyakarta.

Hadari Nawawi, (2005), Manajemen Sumber Daya Manusia Untuk Bisnis Yang Kompetitif, Cetakan Ke-4, Gajah Mada Univercity Press, Yogyakarta.

Hasibuan, Malayu S.P. 2016. Manajemen Sumber Daya Manusia. Edisi Revisi. Jakarta: Penerbit PT Bumi Aksara.

Kasmir. 2016. Manajemen Sumber Daya Manusia (Teori dan Praktik). Depok: PT. Rajagrafindo Persada. 
Mahmudi, 2013, Manajemen Kinerja Sektor Publik. Sekolah Tinggi Ilmu Manajemen YKPN, Yogyakarta.

Pasolong, Harbani. 2011. Teori Administrasi Publik. Yogyakarta: Alfabeta.

Robbins, Stephen P. 2006. Perilaku Organisasi. Jakarta: Salemba 4.

Sedarmayanti. 2009. Sumber Daya Manusia dan Produktivitas Kerja. Bandung: CV Mandar Maju.

Simamora, Henry, 2002. Sumber Daya Manusia, STIE YKPN, Yogyakarta.

Sinambela, Litjan Poltak. 2011. Reformasi Pelayanan Publik: Teori, Kebijakan, dan Implementasi. Jakarta: PT Bumi Aksara.

Sri Sukamti. 2013. Analisis Indeks Kepuasan Masyarakat (IKM) Pada Pelayanan Publik di Puskesmas Kalicacing Kota Salatiga. Jurnal Among Makarti Vol.8 No.15, Juli 2015.

Sugiyono. 2015. Metode Penelitian Pendidikan (Pendekatan Kuantitatif, Kualitatif dan $R \& D$ ). Penerbit CV. Alfabeta: Bandung.

Sutrisno, Edi. 2009. Manajemen Sumber Daya Manusia Edisi pertama. Jakarta: Kencana Prenada Media Group.

Undang-Undang No. 13 Tahun 2003 tentang Hukum Ketenagakerjaan

Undang-Undang Nomor 23 Tahun 1992 tentang Kesehatan

Wirawan. 2009. Evaluasi Kinerja Sumber Daya Manusia Teori Aplikasi dan Penelitian. Jakarta. Penerbit: Salemba Empat. 